\title{
MINGQI OM MENSEN TE BESCHERMEN
}

Dankzij een legaat van E.F. Levie-Philips kwam het Rijksmuseum in 1976 in het bezit van het Chinese aardewerken graffiguurtje van een dienares uit de Han-dynastie (206 v.Chr-220 n.Chr), afbeelding 1. Teneinde de betekenis van dit losse grafobject te kunnen begrijpen, moet men het verband met de ungeving belichten, dat wil zeggen haar relatie met andere objecten en de plaats waar zij zich bevond. Wat was de rol van onze Han-dienares?

\section{Grafgiften}

Al vanaf de oudste tijden was het gewoonte in China om grafgiften mee te geven aan de doden (in elitegraven). De dood veroorzaakte een scheiding van de twee zielen van een mens. Een aardse ziel, po, die achterbleef in het stoffelijk overschot, welke de zorg van de nabestaanden ontving middels begrafenisrituelen en giften. En een hemelse of etherische ziel, hun, die opsteeg naar bovenaardse gebieden. Een niet goed ingericht graf kon ertoe leiden dat de po transformeerde in een kwade geest, gui. Het was dus niet alleen uit respect voor de overledene maar ook om de kwade geesten te bezweren van het grootste belang om de dode rijkelijk te voorzien van geschenken.

Grafgiften zetten de status en privileges die de overledene in het leven had gehad voort en zorgden voor een mate van continuïteit tussen het leven en de dood. De grafgeschenken zorgden ervoor dat de dode ook in het volgende leven een luxueus bestaan kon leiden. Reeds in het Neolithicum bestond de grafinhoud uit potten gevuld met levensmiddelen, stenen gereedschap en wapens. Ook in de Shang-dynastie (c. 1600-1050 v.Chr) en de Zhou-dynastie (1050-221 v.Chr) kregen heersers, edelen en hun echtgenoten hun meest waardevolle bezittingen en veel kostbaarheden mee. Zeer bekend zijn bijvoorbeeld de bronzen rituele vaten van de Zhou die naast hun functie als gift aan edellieden en volgelingen en hun functie als offervaten in vooroudertempels bedoeld waren voor de dode om ook na de dood aan hogere machten offers te brengen (afb. 2). Tijdens de Shang en de Westelijke Zhou (1050-770 v.Chr) was de vooroudertempel onderdeel van het dagelijks leven en werden de graven - buiten de stad - beschouwd als gevaarlijke en

\section{Afbeelding 1}

Dienares, aardewerk met koude beschildering China, Han-dynastie (206 v.Chr.-220 n.Chr.) Rijksmuseum, legaat E.F. Levie-Philips, inv.nr. AK-MAK-1245 ongunstige plekken. ${ }^{1}$ Graven uit die tijd kenden geen opvallende vormgeving met hoge tumuli of bovengrondse architectuur. ${ }^{2}$ Pas tijdens de Oostelijke Zhou vanaf de tijd van de Strijdende Staten (450-256 v.Chr) werd een graf meer zichtbaar in het landschap geplaatst en vonden ook daar de offerrituelen plaats. Het was in die periode dat de bronzen rituele vaten gaandeweg vervangen werden door kleikopieën: vaten die speciaal vervaardigd waren als grafgeschenk. In plaats van authentieke objecten

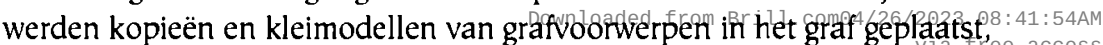


Afbeelding 2

Wijnvat (you), brons

h. $24,8 \mathrm{~cm}$.

China, 10 eeuw v.Chr. Uit: I. Rawson, The British Museum book of Chinese Art, Londen, 1992, afb. 36.

Afbeelding 3 (pag. 21)

Figuren, aardewerk met koude beschildering h. $7,6 \mathrm{~cm}$.

China, $4^{4}$ eeuw v.Chr. Uit: Robert L. Thorp en Richard E. Vinograd, Chinese Art a Culture, New York, 2001, p.11, afb. 3-23

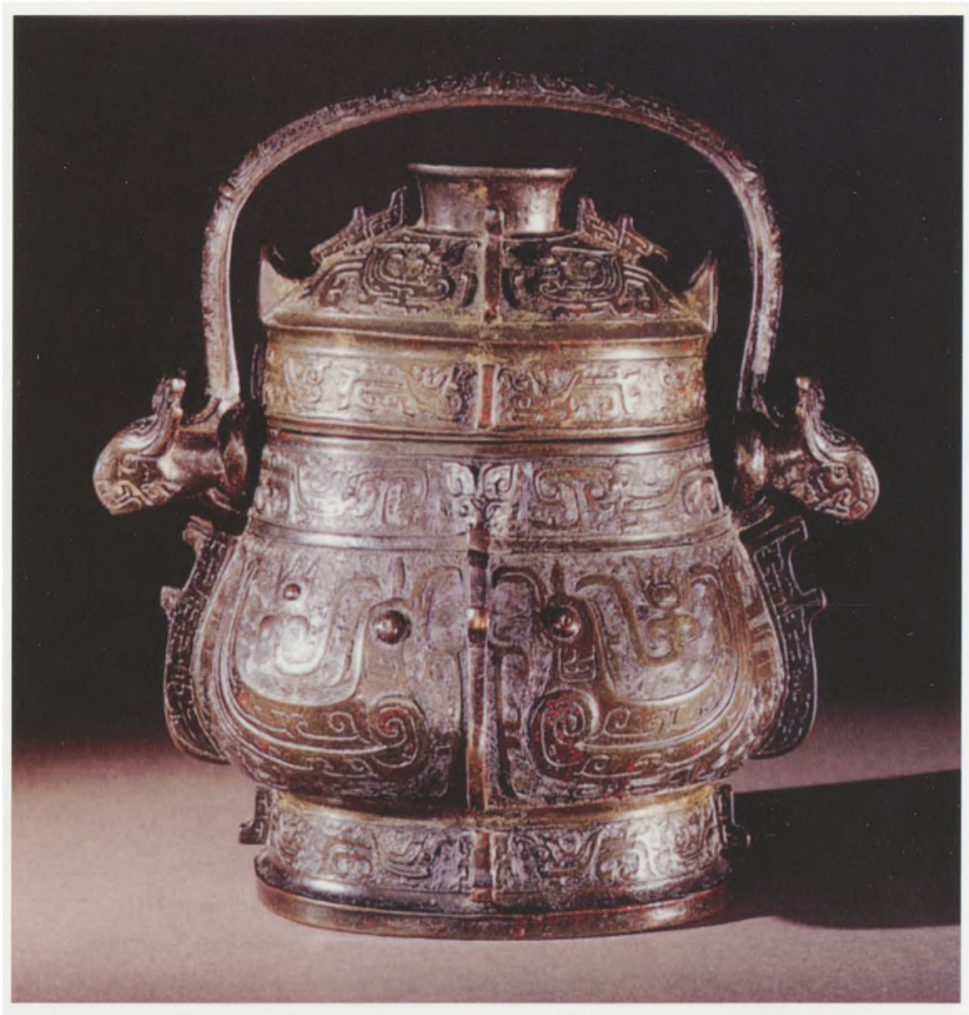

zogeheten mingqi. Deze miniaturen waren speciaal vervaardigd voor de doden om er 'gebruik' van te maken. ${ }^{3}$ De oudste voorbeelden hiervan zijn afkomstig uit de late Shang. $\mathrm{Na}$ de $8^{\mathrm{e}}$ eeuw v.Chr was er een toename van deze mingqi.

\section{Mensenoffers}

In de oudste graven zijn naast voedsel, drank en gebruiksvoorwerpen ook dierenbotten en hondengebitten (onderkaak) aangetroffen. De oudste mensenoffers zijn gevonden in graven van de laat-neolithische culturen. Mensenoffers hadden een noodzakelijke functie; de dode kon niet voortleven zonder hun aanwezigheid. Daarnaast konden de heersers middels de mensenoffers beschikken over leven en dood van volgeling en vijand. Shang- en Zhou-graven konden twintig tot dertig mensenoffers bevatten: mogelijk enkele edellieden, maar vooral mensen van een lagere klasse, zoals bedienden of wagenmenners met hun paard en wagen, uitgerust met een dolkbijl en mes, die hun meester volgden in de dood om hem te helpen en te verdedigen. In de Lente- en Herfstperiode (770-450 v.Chr) van de Oostelijke Zhou werden de meeste mensenoffers gebracht. De hofhistoriograaf Sima Qian schreef rond het jaar 100 v.Chr in de Shiji dat het graf van hertog Jing (577-537 v.Chr) 166 skeletten van mannen en vrouwen bevatte. ${ }^{4}$ Hertog Mu (659-621 v.Chr) eiste nog meer slachtoffers: in totaal 177 personen. $^{5}$ In de $5^{\mathrm{e}}-4^{\mathrm{e}}$ eeuw v.Chr verdween langzaam de gewoonte om dieren- en mensenoffers mee te begraven. In de late Zhou werden voor het eerst naast

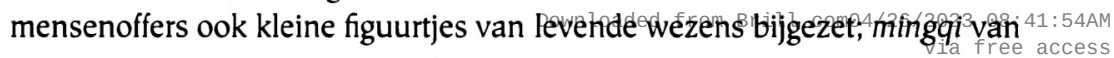




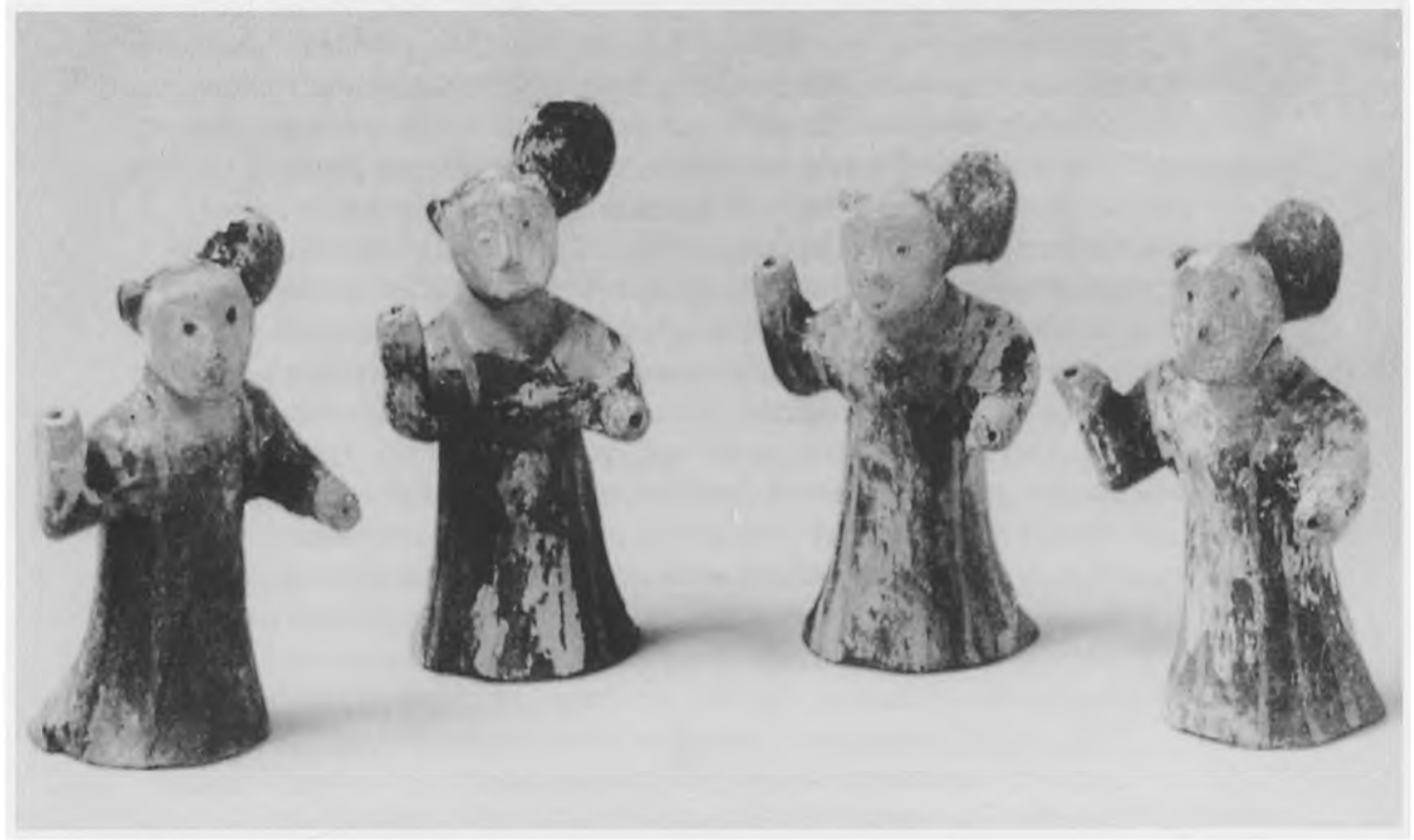

mensen en dieren van klei, terracotta of hout (afb. 3). De oudste vondst hiervan is uit een graf in Langjiazhuang (periode van de Strijdende Staten).

\section{De functie van grafobjecten}

Grafobjecten zou men kunnen indelen op hun functie: ten eerste zijn er objecten met een rituele, magische functie zoals de bronzen vaten uit de Zhou, ten tweede zijn er substituten voor de 'echte' dingen, zoals de mingqi van voorwerpen, mensen en dieren, en ten derde zijn er de persoonlijke, waardevolle objecten van de dode. Volgens Jessica Rawson ontstond er een hiërarchie van behoeften: specifieke personen of dieren die noodzakelijk waren voor het leven van de dode in het hiernamaals, zoals een lievelingsconcubine of een geliefd privé paard, werden geofferd; zij hadden een onmisbare, persoonlijke waarde. Maar voor de meeste andere personen of dieren die nodig waren in het volgende leven, zoals bijvoorbeeld ook onze dienares, kon worden volstaan met kleimodellen; deze figuren hadden een functionele waarde. ${ }^{6}$ Het formaat van deze beeldjes was niet van belang voor hun functie. Er zijn slechts enkele grote mensen- en dierenfiguren gevonden: als wachters voor de ingang van een grafcomplex. Net als ons Han-dienaresje (met een hoogte van $55,2 \mathrm{~cm}$ ) waren de meeste graffiguren niet op ware grootte afgebeeld. De levensgrote soldaten van het terracottaleger van de Eerste Keizer van China (221-210 v.Chr) vormen hierop een uitzondering. Overigens is dit leger niet in het graf van de Keizer zelf begraven, maar dicht in de buurt om hem voor eeuwig te beschermen. (De Eerste keizer had immers

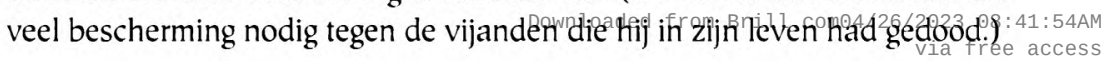


Niet alleen de inhoud van het graf, ook de hele vormgeving van het graf was aan grote veranderingen onderhevig. Geleidelijk veranderde de architectuur van een eenvoudig, verticaal kuilgraf in een horizontale ruimte, die meer en meer de vorm aannam van een onderaardse woning waar het aan niets mocht ontbreken. De overledene was gekleed in dure gewaden, behangen met juwelen en jade. Hij of zij kreeg bijvoorbeeld zijden stoffen, boeken, muziekinstrumenten, schilderingen, voorwerpen van hout of lak en bronzen lampen mee, en kopieën van alledaagse voorwerpen. Het graf werd het huis van de dode. Alles uit de woning van het aardse leven moest eveneens aanwezig zijn in de behuizing van de dode, niet slechts om het dagelijks leven voort te zetten maar ook om de belangrijke rituelen of rituele festiviteiten te kunnen uitvoeren teneinde de kosmologische orde te handhaven. De aardse ziel, po, moest leven in dit graf. In de grafwoning vertegenwoordigden objecten, afbeeldingen en menselijke beeldjes tot in detail het dagelijks leven dat de dode op aarde geleid had. Het graf was rijkelijk gedecoreerd met ornamenten, muurreliëfs, en afbeeldingen van maatschappelijke activiteiten binnen- en buitenshuis. Miniatuurmodellen beeldden diverse scènes uit van het dagelijkse leven: er waren modellen van meubels, werktuigen, boerderijen, huizen, boten, jachttaferelen, landbouwtaferelen (zoals een akker met boerenfiguurtjes erop), torens, edelen, muzikanten en dansers, dienaren, acrobaten, bewakers en huisdieren. Het graf ging steeds meer lijken op de bovengrondse architectuur van een huis met meerdere kamers met elk hun eigen functie en vertegenwoordigde niet alleen de realiteit van het aardse leven, maar idealiseerde deze en zette het voort. ${ }^{7}$ Meer dan duizend jaar - tot in de Ming - zouden deze grafstructuur en het geloof dat de dode moest worden voorzien van al zijn luxe bezittingen hetzelfde blijven.

In de loop van de Zhou kwam er om praktische, economische en ethische redenen een beperking van het aantal mensenoffers. Praktisch aangezien wat eenmaal begraven was nooit meer gebruikt kon worden. Economisch omdat het meebegraven van soldaten of een heel leger de eenheid van de staat ernstig in gevaar bracht: elke vijand zou kunnen binnenvallen in een land dat zich niet verdedigen kon. Een ethisch argument werd door Confucius ${ }^{8}$ aangedragen: hij veroordeelde de mensenoffers om humanitaire redenen. $\mathrm{Al}$ in $383 \mathrm{v}$.Chr verbood een koning van Qin de mensenoffers. Maar in het eerste Chinese keizerrijk was de omslag nog niet geheel voltooid. De eerste keizer van China kreeg niet alleen substituten van een paleis, keizerlijke stallen en een compleet leger met paarden en rijtuigen mee, maar ook echte paarden, edelen, vrouwen en (dwang)arbeiders.

\section{Mingqi}

In de Han-tijd werd het Confucianisme de officiële staatsleer en verdwenen de mensenoffers voorgoed uit de Chinese grafcultuur. Er werden nog slechts mingqi in de graven bijgezet. In de Chinese geschiedenis is nooit zo veel zorg besteed aan het graf en de grafinhoud als in de Han-periode. Zo werd een niet onaanzienlijk bedrag van de staatsuitgaven besteed aan kostbare keizersbegrafenissen. Bij opgravingen van Han-graven zijn zeer veel modellen van mensen tevoorschijn gekomen. De kwaliteit ervan loopt nogal uiteen van heel eenvoudig, met alleen de ruwe kenmerken van een menselijke gestaite

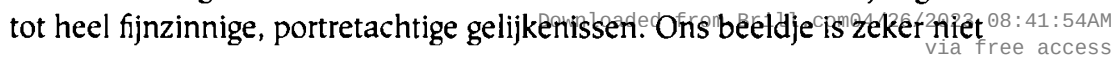


eenvoudig te noemen. Hoewel de vrouw geen portretafbeelding is, is zij zeer levendig vorm gegeven. Haar houding is ingetogen en eerbiedig. Ze draagt een eenvoudige jas met een dubbele overslag, die haar status van dienares uitdrukt.

De beeldjes konden door hun (natuurgetrouwe) afbeelding een magische en beschermende functie vervullen. Waren deze mingqi substituten van mensen? Volgens Jessica Rawson waren het levensechte, werkelijke figuren en niet substituten of voorstellingen van figuren, welke visie volgens haar een laat Westerse rationalisatie is van een fenomeen dat wij niet kunnen bevatten. $\mathrm{Zij}$ betoogt dat mensenoffers en mingqi in elkaars verlengde lagen. ${ }^{9}$ De rol van mingqi was net zo echt als de rol van de mensen die geofferd waren. Slechts om mensenlevens te sparen werden menselijke mingqi ontwikkeld.

De rol van onze Han-dienares bestond eruit dat zij haar meester of meesteres moest helpen in het leven na de dood. Zij is een menselijke mingqi met een belangrijke levensechte betekenis. Ze werd vervaardigd in de Han-periode en dankzij haar bestaan kon de dode zijn luxe bestaan voortzetten na de dood zonder dat het een extra mensenleven vereiste.

\section{Noten}

1. Wu Hung, The Art and Architecture of the Warring States Period. In: Michael Loewe and Edward L. Shaughnessy, The Cambridge History of Ancient China: From the Origins of Civilization to 221 B.C. Cambridge: Cambridge University Press, 1999, p. 707.

2. Ibid., p. 709

3. Ibid., p. 727.

4. Bij de oude hoofdstad Yong (in het district Fengxiang) van de Qin (677-384 v.Chr) zijn 13 graven gevonden. Grafput 1 van hertog Jing is 287 meter lang en 24 meter diep en tot nu toe het grootste graf uit het voor-keizerlijke China dat is opgegraven,, zoals beschreven in: Lothar Ledderose, Ten Thousand Things, Module and Mass Production in Chinese Art. Princeton: Princeton University Press, New Jersey, 1998, p. 65

5. Sima Qian, Shiji, 5:194. Genoemd door Lothar von Falkenhausen in "Ahnenkult und Grabkult im Staat Qin", p.41, in: Jenseits der großen Mauer, L.Ledderose en Adele Schlombs (eds). pp. 35-48

6. Jessica Rawson, "Thinking in Pictures: Tomb Figures in the Chinese View of the Afterlife". In: Transactions of the Oriental Ceramic Society, Vol. 61 (1996-1997), p. 28

7. Lothar Ledderose 1998, p. 66

8. Confucius: $551-479$ v.Chr

9. Jessica Rawson, 1997, pp. 19-37 


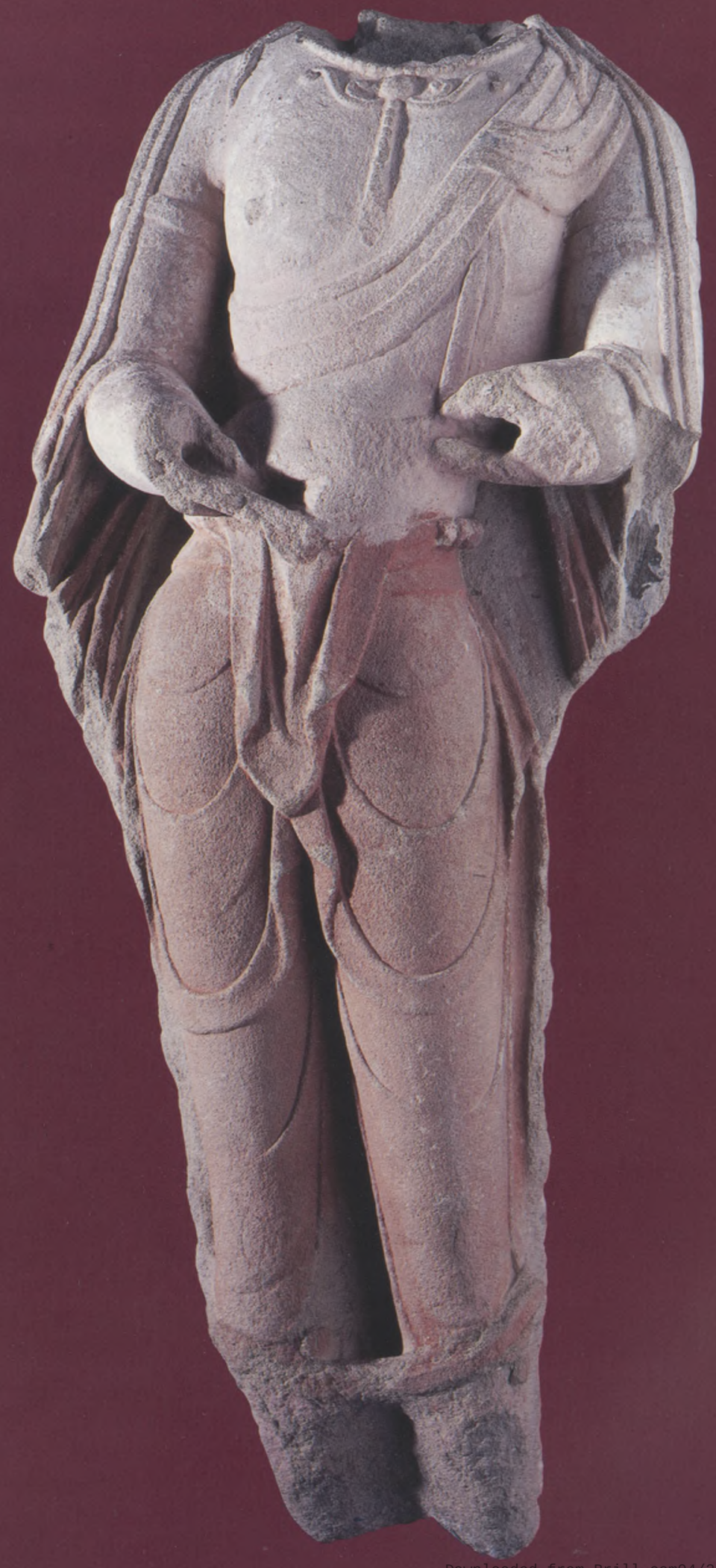

